\title{
Pierre Boaistuau, Histoires prodigieuses (édition de
} 1561)

\section{Michele Mastroianni}

\section{Q OpenEdition}

1 Journals

\section{Edizione digitale}

URL: http://journals.openedition.org/studifrancesi/5567

DOI: 10.4000/studifrancesi.5567

ISSN: 2421-5856

\section{Editore}

Rosenberg \& Sellier

\section{Edizione cartacea}

Data di pubblicazione: 1 septembre 2011

Paginazione: 395-396

ISSN: 0039-2944

\section{Notizia bibliografica digitale}

Michele Mastroianni, «Pierre Boaistuau, Histoires prodigieuses (édition de 1567)», Studi Francesi [Online], 164 (LV | II) | 2011, online dal 30 novembre 2015, consultato il 07 janvier 2021. URL: http:// journals.openedition.org/studifrancesi/5567 ; DOI: https://doi.org/ERREUR PDO dans /localdata/ www-bin/Core/Core/Db/Db.class.php L.34 : SQLSTATE[HY000] [2006] MySQL server has gone away

Questo documento è stato generato automaticamente il 7 janvier 2021.

\section{(c)}

Studi Francesi è distribuita con Licenza Creative Commons Attribuzione - Non commerciale - Non opere derivate 4.0 Internazionale. 


\title{
Pierre Boaistuau, Histoires prodigieuses (édition de 1561)
}

\author{
Michele Mastroianni
}

\section{NOTIZIA}

PIERRE BOAISTUAU, Histoires prodigieuses (édition de 1561), introduction par Stephen BAMFORTH, texte établi par Stephen BAMFORTH et annoté par Jean CÉARD, Genève, Droz («Textes Littéraires Français», 605), 2010, 968 pp.

1 Come appare dall'accuratissima Bibliographie chronologique delle Histoires prodigieuses di Boaistuau (ventiquattro edizioni dal 1560 al 1598, senza contare alcune ristampe conformi o contraffatte; tra il 1569 e il 1670, inoltre, sono segnalate otto traduzioni: una inglese, due in castigliano, cinque in neerlandese) quest'opera, che godette così grande fortuna, non aveva ancora avuto un'edizione critica. Si sapeva che Boaistuau ne aveva dedicato una prima edizione a Elisabetta d'Inghilterra: la recente scoperta del manoscritto offerto alla regina inglese - manoscritto sontuoso, con splendide miniature (oggetto già nel 2000 di un'edizione per bibliofili e storici dell'arte, a cura di Stephen Bamforth, presso l'editore Franco Maria Ricci di Milano) - è servita di base per la prima edizione critica, a cura del suddetto Stephen Bamforth (introduzione e stabilimento del testo) e di Jean Céard (annotazione del testo). Al di là di una fortuna testimoniata dalla diffusione e dal fatto che l'opera di Boaistuau segna non soltanto il punto di arrivo della carriera del suo autore, ma anche la creazione di un genere che sarà praticato fino alla fine del secolo e susciterà numerose continuazioni, le Histoires prodigieuses sono importanti come uno degli esempi più significativi di libro illustrato del Cinquecento. $\mathrm{Ed}$ è il problema iconografico che si pone anzitutto la presente edizione, studiando in particolare l'evoluzione, dal manoscritto (Wellcome Library, 136) alla stampa, non soltanto del testo, ma anche dell'immagine. Inoltre affronta un problema di difficile soluzione, in quanto dal 1560 al 1598, l'opera non cessa di ingrandirsi, al punto che il volume unico dell'inizio diventa una raccolta in sei tomi. Tuttavia, chiarito che le continuazioni successive al testo di partenza (per mano di autori diversi, quali 
Tesserant, Belleforest, Hoyer), per quanto intendano innestarsi sul ceppo delle quarantuno storie composte da Boaistuau stesso, ne sono fondamentalmente indipendenti, gli editori hanno deciso di pubblicare il testo così come fu dato alle stampe dall'autore prima della sua morte. Servendosi poi della collazione sul manoscritto della Wellcome Library, Bamforth sceglie non la prima edizione (del 1560) come base - a differenza di quanto aveva fatto Yves Florenne in una sua edizione per il Club du Livre del 1961 - ma l'edizione del 1561. Esemplare nella ricostruzione dei problemi testuali ed esauriente nel giustificare le scelte editoriali, questa edizione delle Histoires prodigieuses si avvale dell'annotazione ricchissima di Jean Céard che veramente mette in luce le intertestualità di un'opera che dell'erudizione fa il suo punto di forza, e offre i riferimenti storici e antiquari necessari alla comprensione del testo. Ricchissima la bibliografia e accurato il glossario. 